\title{
Dynamic Investment Strategies and Leadership in Product Innovation
}
H. Dawid
M.Y. Keoula
M. Kopel
P.M. Kort 


\title{
Dynamic Investment Strategies and Leadership in Product Innovation *
}

\author{
Herbert Dawid $^{\dagger} \quad$ Michel Y. Keoula ${ }^{\ddagger} \quad$ Michael Kopel ${ }^{\S}$ Peter M. Kort $₫$
}

February 2017

\begin{abstract}
We employ a dynamic market model with endogenous creation of submarkets to study the optimal product innovation strategies of incumbent firms. Firms invest in production capacity and R\&D knowledge stock, where the latter determines the hazard rate of innovation. We find that under Markov Perfect Equilibrium behavior the firm with a larger market share on the established market is less likely to be the first innovator. Investment in R\&D knowledge is negatively affected by the opponent's production capacity on the established market if the opponent has not innovated yet. However, this effect is reversed after the opponent has successfully introduced the new product. The firm with higher costs of adjusting capacity for the established product has a larger incentive to engage in product innovation and might even achieve higher long run profit than its more efficient competitor.
\end{abstract}

Key Words: product innovation strategy, capacity investment, dynamic competition, Markov Perfect Equilibrium

\section{Introduction}

A considerable fraction of product innovations in related submarkets is accomplished by established incumbents (e.g. Chandy and Tellis (2000), Sood and Tellis (2011), King and Tucci (2002), Franco et al. (2009), Buensdorf (2016)). This paper contributes to the strategy dynamics literature by investigating the influence of an incumbent's strength on an established market on the incentive to engage in product innovations for related submarkets and on the timing of new product introduction. Anecdotal evidence seems to suggest a particular pattern for this relationship: firms that possess a relatively high share of the established market tend to enter newly emerging submarkets later than their currently smaller opponents. To illustrate, in 2010 when Apple and Samsung introduced

${ }^{*}$ Financial support from the German Science Foundation (DFG) under grant DA $763 / 4-1$, the Dutch Science Foundation (NWO) under grant 464-11-104, the Flemish Science Foundation (FWO) under grant "G.0809.12N" and COST Action IS1104: "The EU in the new complex geography of economic systems: models, tools and policy evaluation" is gratefully acknowledged.

${ }^{\dagger}$ Department of Business Administration and Economics and Center for Mathematical Economics, Bielefeld University.

${ }^{\ddagger}$ Department of Business Administration and Economics, Bielefeld University.

${ }^{\S}$ Corresponding author: Department of Organization and Economics of Institutions, University of Graz, email: michael.kopel@uni-graz.at, phone: +43 3163807182.

`Department of Econometrics and Operations Research \& CentER, Tilburg University, The Netherlands and Department of Economics, University of Antwerp, Belgium. 
Tablet PCs and thus created a new submarket that coexisted with the established market of portable computers, they had relatively small market shares on the Laptop market (3.4\% and $2.8 \%$ respectively) compared to Hewlett Packard and Dell (18\% and $12 \%$ respectively). Interestingly, HP and Dell entered the Tablet market much later in $2013 .{ }^{1}$ In the market for smartphones, Nokia, as the clear market leader in the early 2000s (market share 2005: $32.5 \%$ ), introduced its first touchscreen phone in 2011, while its initially smaller competitor Samsung (market share 2005: 12.7\%) introduced its first smartphone with a touchscreen in 2008. As a result, Samsung achieved a higher market share in 2012 and also exhibited strongly positive dynamics of profit in the smartphone market compared to Nokia.

The managerial and strategy literature extensively discusses the reasons for the observed pattern that big incumbents are often slower than smaller rivals (or entrants) in pioneering newly created submarkets. There are at least four approaches that can be distinguished and they share the view that the relatively slow adoption of innovation by big incumbents leads to suboptimal outcomes from a long term firm perspective. First, incumbents underinvest in the development of new technologies or products due to the fear of cannibalizing its existing business. In line with this view, it has been argued, e.g. in Nault and Vandenbosch (1996), that incumbent firms have to 'eat their own lunches before somebody else does'. In particular, this literature suggests that a market leader's optimal strategy is to aggressively cannibalize its own current advantages by next-generation innovations before competitors step in to steal the market.

Second, large firms might lack the potential of small firms to motivate their engineering staff. The associated bureaucracy and incentive effects lead to lower innovation intensity (e.g. Zenger (1994)). Third, big incumbent firms might rely on a dominant managerial logic, organizational capabilities and cognitive frames that lead these firms - sometimes even after large sums of investments - to miss new opportunities (e.g. Christensen (1997), Henderson (1993, 2006), Tripsas (1997), Tripsas and Gavetti (2000)). Fourth and finally, incumbent firms are less successful in innovation since there are diseconomies of scope which arise from key assets that have to be shared across businesses (Bresnahan et al. (2012)). In contrast to these explanations that focus on the suboptimality of firms' decisions, our paper shows that the strategy of large incumbents to enter a new market relatively late follows from intertemporally optimal behavior of all firms in the market. In a multi-product setting in which the original market continues to attract consumers even after the new submarket has been created, the decision of the dominant incumbent firm to get leapfrogged by a smaller rival that enters the new submarket earlier, simply results from pursuing long run profit maximization. The conclusion is that leader firms might prefer not to maintain leadership due to their involvement in existing market segments (see also Pacheco-de-Almeida (2010), Swinney et al. (2011)).

More precisely, the main contribution of our paper is to characterize the intertemporally optimal innovation behavior of incumbent firms in an industry with evolving market structure. In such an industry, a submarket is created endogenously by an incumbent's product innovation. In accordance with the dynamic pattern described above, our study leads to the conclusion that the expected innovation time of large incumbents is larger than the innovation time of its smaller competitors. The main driving force of this finding is that an incumbent's resource commitment on the established market (in terms of production capacity) has a negative impact on the incumbent's incentive to investment in firm-specific resources that are key for product innovation. In particular, we argue that a firm's incentive to invest is determined by a size effect and a pure knowledge effect, apart from the well-known cannibalization effect. Considering a scenario of initial resource het-

\footnotetext{
${ }^{1} \mathrm{HP}$ made a short - but unsuccessful - premature attempt of offering a Tablet PC in 2010.
} 
erogeneity, e.g. where the incumbents differ with respect to their technology of building up resources for production on the established market, the interaction of these effects implies that the firm with a cost disadvantage on the established market invests more in building up key resources for product innovation and, therefore, expects to innovate faster. In such a situation, it might turn out that a cost-disadvantaged incumbent on the established market can actually have a higher value function (expected discounted profits) than its more cost-efficient opponent. In other words, despite having a competitive disadvantage (at a point in time), an incumbent firm can have superior performance (in the long run). Intuitively, in equilibrium the cost disadvantage acts as a strategic commitment device of the firm to make large investments in firm-specific resources for innovation, which in turn causes reduced innovation activities by its competitor.

Additionally, our analysis generates new managerial insights about the qualitative properties of the firms' optimal strategies for investing in and developing resources for product innovations. Analyzing a dynamic industry model enables us to highlight qualitative differences between the optimal strategy for building up key resources for product innovation in a phase where competition only occurs on the established market and a phase after a competitor has created a new submarket by its product innovation. We find that innovation activity is negatively affected by the opponent's production capacity on the established market if the opponent has not innovated yet. However, this effect is reversed after the opponent has successfully innovated. Furthermore, the optimal level of a firm's investment in firm-specific R\&D resources exhibits a downward jump at the time when the opponent creates the new submarket, since the discounted profit stream generated by the firm's product innovation drops once the competitor is active on the new market. After this discontinuous change in the firm's investment level, the optimal investment pattern exhibits a steady adjustment. This pattern might be increasing or decreasing over time, however it always stays below the investment level prior to the opponent's innovation. An important managerial implication of this finding is that the innovation strategy of a firm has to be carefully re-evaluated, both with respect to the level of R\&D investment and its response to the opponent's capacity adjustments, once the competitor has won the innovation race.

More technically, our analysis is based on Markov Perfect Equilibria in a dynamic duopoly model. Initially, the two incumbent firms offer an established homogeneous product. Both firms have the possibility to build up a firm-specific resource (referred to as $R \& D$ knowledge stock) that is essential for product innovation. The possibility to invest in production capacity and to launch the new product arises if a firm's R\&D project is successfully completed where the exact time when the breakthrough occurs is unknown (stochastic) to the firms. Each firm's hazard rate of innovation is a function of both the accumulated knowledge stock and its current investment in the R\&D knowledge stock. At an ex-ante unknown point in time, the range of products of one of the firms is enlarged by introduction of a new product which is an (imperfect) substitute for the existing product and is vertically and horizontally differentiated. When the first innovator introduces this new product, a new submarket is created and the innovator can then start to invest in the development of resources for production of the new product. The rival firm might enter this new submarket later, once its own R\&D project has been completed. Firms adjust their production capacities for the product(s) through costly (dis)investments. Capacities cannot be (fully) transferred between the production of different products. A firm's objective is to maximize its expected total discounted profits by optimally investing in production capacities for the (existing and new) products it offers and, before the new product is introduced, by optimally investing in $\mathrm{R} \& \mathrm{D}$ knowledge stock. 
To capture the structural breaks in the industry dynamics that are triggered by the (stochastic) endogenous creation of new submarkets by incumbents, a piecewise deterministic (also called multi-mode) differential game is employed. The introduction of the new product by each of the incumbents corresponds to a transition between different modes of the game. To characterize a Markov Perfect Equilibrium in this game of complex structure and high-dimensional state space, we rely on a numerical collocation approach using sparse grid methods. Although sparse grid methods have been recently applied in dynamic macroeconomic models (e.g. Malin et al. (2011)), as a technical contribution our paper illustrates the potential of such an approach for strategy dynamics, in particular for analyzing optimal firm strategies in a dynamic industry model.

Intuitively, the interplay of three effects determine the characteristics of the equilibrium feedback functions which describe the firms' R\&D strategies. First, the total production capacity on the established market influences the price of the product on the new submarket negatively. This, in turn, reduces the incentives to enter that market. We label this as the size effect (see also Dawid et al. (2013)). Second, the dynamics of the investments in $R \& D$ knowledge stock is strongly influenced by the pure knowledge effect (see Doraszelski (2003)). R\&D incentives are negatively influenced by the firm's current hazard rate because after its $R \& D$ project has been completed, the accumulated stock of R\&D knowledge becomes obsolete for the firm. In particular, the pure knowledge effect explains why after a downward jump of R\&D investment at the time of the creation of the new submarket, it can be optimal for the firm to subsequently increase its R\&D activity. Third, sales in the new submarket have a negative effect on the price of the established product. This is the well-known cannibalization effect which affects the incumbents' profits on that market negatively (e.g. Moorthy and Png (1992), Desai (2001), Yayla-Küllü et al. (2013)). Hence, the cannibalization effect negatively influences the R\&D incentive of an incumbent and is stronger the larger the firm's capacity on the established market. Note that the size effect depends on both the firm's own and the opponent's capacity on the established market. In contrast, the cannibalization effect only concerns the firm's own capacity. Hence, although prior to the creation of the new submarket the firm's intensity to invest in the R\&D knowledge stock is negatively affected both by the own and the competitor's capacity, the effect of the own capacity on R\&D incentives is stronger. This explains why the incumbent with larger capacity on the established market invests less in product innovation. The downward jump of the firm's R\&D investment at the time when the new submarket is created by the competitor is driven by the fact that before this time the firm expects to be the first innovator with positive probability, hence expects to obtain high profits as the only supplier of the new product.

The paper is organized as follows. The next section gives a brief overview of the related literature. Then, Section 3 introduces the model and details its assumptions. Section 4 is devoted to a characterization of the firms' optimal investment strategies. Section 5 explores how strategies to invest in R\&D knowledge stock are affected by the (relative) firm size on the established market before the new market emerges. Section 6 highlights that the laggard's equilibrium strategy of investing in R\&D after the successful product innovation of its competitor qualitatively differs from the optimal strategy during the innovation race. A scenario in which the firms differ with respect to their investment costs on the established market is considered in Section 7. We show that despite such a persistent structural disadvantage, the less efficient firm might have a comparative advantage in the long run. Section 8 analyzes how R\&D incentives and innovation speed differ between duopoly and monopoly. Section 9 concludes and discusses which testable empirical implications follow from our analysis. The Appendix provides details about the derivation and numerical 
calculation of the Markov Perfect Equilibria, confirms the robustness of our results with respect to parameter variations and gives a formal treatment of the determination of the socially optimal strategy.

\section{Literature}

Our paper is related to several important lines of research in the literature. First, on a general level it contributes to recent research which focuses on dynamic models of firm strategies under competitive interactions (e.g. Ghemawat and Cassiman (2007), CasadesusMasanell and Yoffie (2007), Sterman et al. (2007), Casadesus-Masanell and Ghemawat (2006), and Adner and Zemsky (2006)).

More specifically, Pacheco-de-Almeida and Zemsky (2007) consider a duopoly setup in which an exogenously determined leader invests over time to obtain a resource, which gives a competitive advantage. Once the leader has the resource, the follower can start investing to obtain that resource as well in order to level the playing field on the market. They characterize under which circumstances the follower has incentives to invest and therefore catches up with the leader. Building on this, they determine the optimal investment strategy of the leader in such a scenario as well as in one where the leader does not have to fear that the follower catches up. In particular, the authors show that there is a higher incentive to develop the resource in the latter case. Our setup is related to that in Pacheco-de-Almeida and Zemsky (2007) as we also consider the different phases of duopoly competition before the first innovation, after the first innovation, and after both firms have innovated. However, different from their paper, in our setting the first phase is characterized by innovation competition such that innovation leadership is endogenously determined. Furthermore, whereas in Pacheco-de-Almeida and Zemsky (2007) the instantaneous profits for the two firms in the different phases of competition are constant and given, we endogenize these profits as functions of both firms' production capacities. This allows us to study the relationship between incentives to invest in R\&D and investments in strengthening the competitive position on the existing markets.

Pacheco-de-Almeida (2010) studies an environment where a leader firm's competitive advantage gets eroded by imitation and innovation in a hypercompetitive environment. He derives conditions under which the leader should optimally "self-displace" itself by investing less in renewing its competitive advantage, thereby increasing the probability of getting displaced by a rival. Similarly, we consider an incumbent leader that is currently more profitable due to an advantage in market share or in investment costs for accumulating production resources and argue that it is rational for the leader to opt for self-displacement. With respect to characterizing dynamic strategies, our approach differs in that we characterize Markov Perfect Equilibria of an underlying dynamic game, whereas in Pacheco-de-Almeida (2010) no dynamic strategic interaction between the competitors is considered.

Like in Pacheco-de-Almeida and Zemsky (2007) and Pacheco-de-Almeida (2010), our work is also concerned with the impact of accumulation of asset stocks, time compression diseconomies, and asset erosion (e.g. Dierickx and Cool (1989)) on a firm's dynamic R\&D strategy and innovation timing. An important difference is that in these contributions the firm exactly knows the level of accumulated effort needed to achieve the resource development, whereas in our setting the time of the firms' innovation breakthrough is stochastic. Therefore, firms can only influence the distribution of innovation times, but cannot fully determine them. In this respect our setup is related to Breton et al. (2006), who consider a dynamic duopoly game and assume that firms invest in knowledge stocks, which 
subsequently determine the probability of successful R\&D. However, while they consider process (i.e. cost-reducing) R\&D, we study product innovations and the associated sudden change in market structure. Furthermore, our model also takes into account that resources for production have to be accumulated over time.

Ofek and Sarvary (2003) is related to our setting by employing a dynamic game for studying the incentives of incumbent firms to invest in R\&D. However, they assume that firm-specific hazard rates depend only on current investments, whereas we capture the need to accumulate an R\&D knowledge stock and resources for production. Additionally, we take into account the linkage between the existing market and the new market and its effect on the firms' profits. Like us, Mitchell and Skrzypacz (2015) consider a model of industry evolution with endogenous creation of submarkets by incumbents and entrants. However, their analysis is on the industry level, whereas our focus is on optimal innovation strategies at the firm level, as we study the incumbents' optimal intertemporal investment strategies.

The second line of related literature deals with disruptive innovations and also tries to answer the question why leading incumbents are slower to enter newly created submarkets than their smaller rivals. Christensen (1997) argues that differences in the internal resource allocation processes and dominant managerial logics of large and small firms result in the 'Innovator's Dilemma'. This leads to the outcome that large incumbent firms might fail to react appropriately to the emergence of new disruptive technologies or business models. In an analytical model of Cournot competition with horizontal and vertical differentiation, Adner and Zemsky (2005) characterize how the boundaries of technology competition depend on various properties like rates of technological advance, the number of firms which use the old and the new technology, relative market segment sizes, and the ability of firms to price discriminate. In contrast to work on disruptive innovation, we do not consider drastic or radical innovations as in our model existing and new market segments are coexisting. Moreover, we argue that the leader incumbent's decision to enter the new submarket late is perfectly consistent with the goal of long run profit maximization. In a recent paper, Wu et al. (2014) provide an alternative view on disruptive innovations. They argue that it might be preferable for incumbents to offer their new products in a smaller niche (on a complement-preserving trajectory) in order to leverage their existing complementary assets rather than to compete head-to-head with their rivals (along a complement-disrupting trajectory). While we share the view of Wu et al. (2014) that the decision of big incumbents to retreat to a smaller niche might be optimal, our main line of reasoning is that the accumulation of essential resources for production and innovation takes time and is costly. Swinney et al. (2011) study how the timing of capacity investment differs between incumbent and new firms when they enter new markets. Like us, they find an asymmetric equilibrium where a (smaller) start-up builds capacity early and enters the new market first while a (larger) incumbent optimally enters later. In contrast to their model, we consider the continuous accumulation of production capacities (and R\&D knowledge stocks) and capture the endogenous creation of submarkets. Schmidt and Porteus (2000a,b) and Huang and Sosic (2010) study the incentives of an incumbent and an entrant to enter a new market. Dawid et al. (2013) consider a setting with two incumbents that can both enter a new market. In contrast to our paper, their models are static and, hence, these papers do not contribute to the questions of optimal accumulation of resources for production and innovation and the resulting optimal innovation timing.

From a technical perspective, our paper is further related to the literature on capital accumulation games in industrial organization (e.g. Jun and Vives (2004), Lapham and Ware (1994)), in which capacity investments of single-product firms engaged in oligopolis- 
tic competition have been characterized both in the framework of open-loop and Markov Perfect Equilibria. Besanko and Doraszelski (2004) introduce a capacity accumulation game in discrete time to characterize an evolving industry structure and to explain the persistence of differences in firm size (cf. also Doraszelski and Pakes (2007), Escobar (2013)). Besanko et al. (2010) study capacity accumulation patterns in a discrete-time dynamic duopoly game with strategic uncertainty (about the rival's cost) and find that the occurrence of preemption races (where excess capacity is built up) and capacity coordination (where capacities are close to cartel levels) depend on the degree of product differentiation, investment sunkness, and capacity depreciation. This literature, however, has not dealt with capacity adjustment processes in cases where a firm's product line consists of more than one product. Furthermore, this literature does not deal with the firms' incentive to change the size of their product range.

Our paper relates also to research on differential R\&D games, for example Cellini and Lambertini (2002, 2009), or Lambertini and Mantovani (2009). In contrast to us, they focus either on product innovation or on process innovation of single-product firms, or on the interaction between these two types of innovation. Hence, they do not study the issue of incumbents who face the problem of launching new products and have to accumulate resources for production and innovation over time.

\section{The Model}

We consider a dynamic duopoly in continuous time with evolving market structure. Initially, two incumbent firms A and B produce a homogeneous product called product 1. We refer to product 1 as the established or 'old' product. Both firms invest in the accumulation of an R\&D knowledge stock which is essential to develop a new differentiated product, called product 2 . Let $\tau_{A}$ and $\tau_{B}$ be the stochastic completion times of the firms' R\&D projects. Once one of the firms has innovated, a new submarket can be created. ${ }^{2}$ At this stage only the innovator can sell both products 1 and 2, whereas the laggard is selling the established product while simultaneously investing in R\&D knowledge stock to eventually enter the new submarket as well. Once both firms have innovated, products 1 and 2 are supplied by both firms. In the sequel, we refer to both firm A and B by subscript $f(f=A, B)$ but keep the distinction whenever it is necessary.

To enable production, firms A and B need production capacities, denoted by $K_{i f}(t), i=$ $1,2, f=A, B$. In the stage prior to the creation of the new submarket, called mode $m_{1}$, both firms invest in their production capacity $K_{1 f}(t)$ for product 1 and invest in the accumulation of their firm-specific $\mathrm{R} \& \mathrm{D}$ knowledge stock $K_{R f}(t)$. In the stage after the new submarket has been created, corresponding to mode $m_{2}$ (mode $m_{3}$ ) where firm A (firm B) innovates first, the firm that has first completed the $R \& D$ project invests in production capacity for both products. The laggard continues to invest in capacity for product 1 and its $\mathrm{R} \& \mathrm{D}$ knowledge stock. In the last phase or mode $m_{4}$, which emerges after the innovation of the laggard, firms compete on both markets and (dis)invest in both production capacities. Production capacities and R\&D knowledge stocks accumulate according to

$$
\dot{K}_{i f}(t)=I_{i f}(t)-\delta_{i} K_{i f}(t) \quad i=1,2, R, \quad f=A, B,
$$

where $I_{i f}(t)$ is the investment of firm $f$ in stock $K_{i}$ at time $t$. These standard dynamics account for the fact that accumulation of resources for production and innovation take

\footnotetext{
${ }^{2}$ The submarket is actually created once the innovator invests in production capacity for the new product and hence this product is produced and sold on the market.
} 
time, but also that asset erosion takes place where $\delta_{i}>0, i=1,2$ denote the (symmetric) depreciation rates. With regard to the $\mathrm{R} \& \mathrm{D}$ knowledge stock, organizational forgetting (see Doraszelski (2003) and references therein) is captured by $\delta_{R}>0$.

Concerning production resources, we allow the firms to intentionally disinvest, i.e. $I_{\text {if }} \in \mathbb{R}$. With regard to the R\&D knowledge stocks, we make the sensible assumption that knowledge investments are non-negative, i.e. $I_{R f} \geq 0$. The firms cannot invest in production capacity of the second product before the R\&D project has been completed, which implies that $I_{2 f}(t)=0$ for all $t<\tau_{f}$.

Furthermore, all stocks have to be non-negative:

$$
K_{i f}(t) \geq 0 \quad \forall t \geq 0 \quad i=1,2, R, f=A, B .
$$

The arrival of the innovation of firm $f$ is determined by a firm's hazard rate $\lambda_{f}$ which is a function of the current investment $I_{R f}(t)$ in the R\&D knowledge stock as well as the R\&D knowledge stock $K_{R f}(t)$ itself. We employ an additive form of the hazard rate (see Doraszelski (2003)), given by

$$
\lambda\left(I_{R f}(t), K_{R f}(t)\right)=\alpha I_{R f}(t)+\beta K_{R f}^{\psi}(t), \alpha \geq 0, \beta \geq 0, \psi>0, \quad f=(A, B) .
$$

The probability for a firm's successful innovation is positively affected by its current level of investment in resources for innovation and its accumulated knowledge through past R\&D activities. The chosen formulation of the hazard rate captures this property in the most simple way. The parameters $\alpha$ and $\beta$ determine, respectively, the marginal impact of the current investment and the accumulated knowledge on the hazard rate. In what follows we will focus on scenarios where $\psi>1$, i.e. where the firm's hazard rate is strictly convex in its R\&D knowledge stock. This is in line with evidence that points to the cumulative nature of R\&D activities (e.g. Dosi (1988)), and it implies that the effect of a marginal increase of $\mathrm{R} \& \mathrm{D}$ knowledge grows with the current level of the R\&D knowledge stock.

Formally, the changes between the modes of the game are described by a Markov process $m(t)$ on the state space $M=\left\{m_{1}, \ldots, m_{4}\right\}$ where the transition rates are given by

$$
\lim _{\Delta \rightarrow 0} \frac{1}{\Delta} \operatorname{Prob}\left\{m(t+\Delta)=m_{j} \mid m(t)=m_{i}\right\}= \begin{cases}\lambda\left(I_{R A}, K_{R A}\right) & (i, j)=(1,2),(3,4), \\ \lambda\left(I_{R B}, K_{R B}\right) & (i, j)=(1,3),(2,4), \\ 0 & \text { else. }\end{cases}
$$

This formulation embodies the idea that before the creation of the new submarket (i.e. in mode $m_{1}$ ) there are positive probabilities of transition either to mode $m_{2}$ with firm $\mathrm{A}$ as innovator or to mode $m_{3}$ with firm B as innovator. From modes $m_{2}$ or $m_{3}$, the transition has to switch to mode $m_{4}$, where both firms offer both products. The expected time of this final transition depends on the hazard rate of the innovation laggard. Once both firms offer both products no more transitions are possible.

At any point in time $t$ firms compete in quantities, where it is assumed that current production capacities for the two products are always fully exploited. This assumption is commonly made in the literature on capacity-constrained oligopoly competition (e.g. Anand and Girotra (2007), Goyal and Netessine (2007) and Huisman and Kort (2015)). For example, Goyal and Netessine (2007) argue that firms may find it difficult to produce below capacity due to fixed costs associated with, for example, labor inputs, commitments to other suppliers, or production ramp-up. Given this assumption, prices are given by the linear inverse demand system (e.g. Lus and Muriel (2009)): 


$$
\begin{aligned}
& p_{1}(t)=1-\left(K_{1 A}(t)+K_{1 B}(t)\right)-\eta\left(K_{2 A}(t)+K_{2 B}(t)\right) \\
& p_{2}(t)=1+\theta-\eta\left(K_{1 A}(t)+K_{1 B}(t)\right)-\left(K_{2 A}(t)+K_{2 B}(t)\right) .
\end{aligned}
$$

In this setting, the parameter $\eta(-1<\eta<1)$ determines the degree of horizontal differentiation between the established and the new product. We restrict attention to scenarios where the new product is a partial substitute of the established product, corresponding to $\eta>0$. Accordingly, a firm's dynamic strategy of building up capacities for the established product and the new product is inextricably linked through its impact on the prices of the products on the two markets. The parameter $\theta$ determines the degree of vertical differentiation and measures the difference in quality between the new product and the established product. The assumption that product 2 is at least of the same quality as product 1 translates into $\theta \geq 0$.

Investment costs are assumed to have the linear-quadratic form

$$
\Gamma_{i f}\left(I_{i}(t)\right)=\mu_{i f} I_{i f}(t)+\frac{1}{2} \gamma_{i} I_{i f}(t)^{2} \quad i=1,2, R .
$$

This formulation captures time compression diseconomies for building up resources for production and innovation. The parameter $\mu_{i f}$ represents the unit price of capacity for product $i(i=1,2)$ or the unit price of the knowledge capital $(i=R)$. The parameter $\gamma_{i}>0(i=1,2, R)$ is the adjustment cost parameter. In our default setting all cost parameters are symmetric across firms and asymmetry between firms arises due to initial resource heterogeneity. However, in order to be able to study the impact of structural (dis-)advantages of a firm on a certain market we also allow investment costs to differ between the firms. For simplicity, marginal production costs are normalized to zero.

Firms choose their investment strategies in order to maximize their expected infinite horizon discounted profit stream. Formally, we have

$$
\begin{aligned}
& J_{f}=\mathbb{E}\left\{\int _ { 0 } ^ { \infty } e ^ { - r t } \left[\left(1-\left(K_{1 A}+K_{1 B}\right)-\eta\left(K_{2 A}+K_{2 B}\right)\right) K_{1 f}\right.\right. \\
&+\left(1+\theta-\eta\left(K_{1 A}+K_{1 B}\right)-\left(K_{2 A}+K_{2 B}\right)\right) K_{2 f} \\
&\left.-\mu_{1 f} I_{1}-\frac{\gamma_{1}}{2} I_{1}^{2}-\mu_{2 f} I_{2}-\frac{\gamma_{2}}{2} I_{2}^{2}-\mu_{R f} I_{R}-\frac{\gamma_{R}}{2} I_{R}^{2}\right] d t
\end{aligned}
$$

where the expectation is taken with respect to the mode dynamics. The first two lines capture the instantaneous sales revenue for the established product and the new product. The third line contains the current costs of investment in production capacity and R\&D knowledge stock. It should be noted that in modes where a firm has not introduced the new product yet, both investment and production capacity for that product are zero, such that the corresponding terms vanish in the instantaneous profit function.

This gives rise to a piecewise deterministic differential game with objective functions (8), the state dynamics (1) and the mode dynamics (4). Since a firm can build up capacity for the new product only after the new submarket has been created and it has added the new product to its product line, this implies that the following constraints hold in the different modes:

$$
\begin{aligned}
& I_{2 f}(t)=0, \forall t \text { s.t. } m(t)=m_{1}, \quad f=A, B \\
& I_{2 B}(t)=0, \forall t \text { s.t. } m(t)=m_{2}, \\
& I_{2 A}(t)=0, \forall t \text { s.t. } m(t)=m_{3} .
\end{aligned}
$$


Non-negativity constraints for production capacities, the R\&D knowledge stock, and the investments in R\&D knowledge stock have to be satisfied. To study how the anticipation of the emergence of a new submarket impacts firms' current investments in resources for production and innovation, we assume that the game starts before the new submarket has been created. That is, $m(0)=m_{1}$ and the initial values of production capacities and the $\mathrm{R} \& \mathrm{D}$ knowledge stock are given by $K_{1 f}(0)=K_{1 f}^{i n i}, K_{2 f}(0)=0, K_{R f}(0)=K_{R f}^{i n i}$.

\section{Dynamic Investment Strategies}

In order to analyze optimal strategies for investing in resources for production and innovation, we consider stationary Markov Perfect Equilibria (MPE) of the game. A stationary Markovian strategy of firm $f$ is given by a triple $\left(\phi_{1 f}, \phi_{R f}, \phi_{2 f}\right)$ such that each of the feedback strategies $\phi_{i f}$ and $\phi_{R f}$ describe the optimal dynamic investment for accumulating production capacity and $R \& D$ knowledge as a function of the states and the current mode of the game. More precisely, each of these feedback strategies has the form $\phi_{i f}:[0,1]^{2} \times$ $\left[0, \bar{K}_{R}\right]^{2} \times[0,1+\theta]^{2} \times M \mapsto \mathbb{R}$ for $i \in\{1,2\}$ and $\phi_{R f}:[0,1]^{2} \times\left[0, \bar{K}_{R}\right]^{2} \times[0,1+\theta]^{2} \times M \mapsto \mathbb{R}_{0}^{+}$. The upper bound of the R\&D knowledge stock $K_{R}$ is assumed to be sufficiently large to ensure that the stable steady states characterized in the following analysis are interior. Although we write the feedback strategies in this general form, clearly some arguments are irrelevant in some modes. In particular, due to the investment constraints in the different modes, $\phi_{2 f}=0$ has to hold in mode $m_{1}$ since no investment in production capacity of the new product is possible before the product innovation is successful. For the non-innovator the same holds in mode $m_{2}$ or $m_{3}$. Furthermore, we have $\phi_{R A}=0\left(\phi_{R B}=0\right)$ in mode $m_{2}\left(m_{3}\right)$ and $\phi_{R f}=0, f=A, B$, in $m_{4}$ since no more innovations are possible. Similarly $K_{2 f}, f=A, B$, is by assumption equal to zero in mode $m_{1}$ and $K_{R f}$ is irrelevant in mode $m_{4}$. The same reasoning implies that also in modes $m_{2}$ and $m_{3}$ only four state variables are relevant. To ease notation, in what follows we will drop all irrelevant arguments in the corresponding modes. As a notational convention, the first and third argument in the feedback functions of both firms always refer to stock variables of firm A, whereas the second and fourth to stock variables of firm B. In accordance with the literature (see Dockner et al. (2000)) we only consider non-anticipating strategies, i.e. strategies where firms cannot condition their actions on realizations of the time of mode transitions which lie in the future.

A Markov Perfect Equilibrium of the game is a profile of stationary Markovian strategies, where each firm uses a strategy maximizing expected profit given the strategy of the opponent. In order to characterize such equilibrium profiles, a set of Hamilton-JacobiBellman (HJB) equations has to be solved, containing one equation for each player in each mode. The multi-mode structure of the game implies that the value functions in the different modes are linked through terms in the HJB equations that capture the jumps in the firms' value at the times an innovation occurs. Using these equations we obtain the following proposition, which is proved in Appendix A.

Proposition 1. The feedback strategies in a Markov Perfect Equilibrium of the game are 
given by

$$
\begin{aligned}
\phi_{i f}^{*}(., m) & =\frac{1}{\gamma_{h}}\left(\frac{\partial V_{f}(\cdot, m)}{\partial K_{i f}}-\mu_{i f}\right), i=1,2, f=A, B, m \in\left\{m_{1}, . ., m_{4}\right\} \\
\phi_{R A}^{*}\left(., m_{1}\right) & =\frac{1}{\gamma_{R}}\left(\frac{\partial V_{A}\left(\cdot, m_{1}\right)}{\partial K_{R A}}-\mu_{R A}+\alpha\left(V_{A}\left(\cdot, m_{2}\right)-V_{A}\left(\cdot, m_{1}\right)\right)\right) \\
\phi_{R B}^{*}\left(., m_{1}\right) & =\frac{1}{\gamma_{R}}\left(\frac{\partial V_{B}\left(\cdot, m_{1}\right)}{\partial K_{R B}}-\mu_{R B}+\alpha\left(V_{B}\left(\cdot, m_{3}\right)-V_{B}\left(\cdot, m_{1}\right)\right)\right) \\
\phi_{R f}^{*}(., m) & =\frac{1}{\gamma_{R}}\left(\frac{\partial V_{f}(\cdot, m)}{\partial K_{R f}}-\mu_{R f}+\alpha\left(V_{f}\left(\cdot, m_{4}\right)-V_{f}(\cdot, m)\right)\right), \begin{array}{c}
f=A, B, \\
m=m_{2}, m_{3}
\end{array},
\end{aligned}
$$

where $V_{f}\left(K_{1 A}, K_{1 B}, K_{R A}, K_{R B}, K_{2 A}, K_{2 B}, m\right)$ denotes the value function of firm $f=A, B$ in mode $m \in M$.

Investment in production capacity of the established product and the new product is proportional to the difference between the marginal effect of an increase in capacity on the firm's value function and the unit price of capacity (see (9)). Concerning a firm's investment in R\&D knowledge stock, an additional effect arises because such an investment increases the hazard rate of making the transition to a different mode where the firm is active on both markets. This mode transition induces a jump in the value function and the corresponding effect is captured by the last terms in (10) to (12).

The main technical and computational challenge is to solve the underlying set of HJB equations of our differential game with stochastically evolving market structure. Due to the fact that the hazard rates are non-linear functions of the state variables, these equations, apart from mode $m_{4}$, do not allow for closed-form (polynomial) solutions. Hence, we rely on numerical collocation methods for the computation of the value functions in the different modes. ${ }^{3}$ Furthermore, the large dimension of the state space requires the application of sparse grid methods in the collocation (see Maliar and Maliar (2014)). Details of the method used in our analysis are given in Appendix B. For all results presented in the following sections it has been checked that the transversality conditions are satisfied in all modes.

In what follows, we present numerical results obtained by this approach for the baseline parameter setting given in Table 1 . The unit price of production capacity, $\mu_{i}$, is normalized to zero, but the values of the adjustment cost parameters, $\gamma_{i}$, are positive. To capture the interplay between the markets, the degree of horizontal differentiation is assumed to be $\eta=0.65$. We deal with a scenario where the difference in qualities between the new product and the old product is moderate, which is reflected by $\theta=0.2$. Depreciation rate and interest rate are set to standard values. As discussed above, we assume that the hazard rate is a strictly convex function of the firm's R\&D knowledge stock $(\psi=2)$. The coefficients $\alpha$ and $\beta$ of the hazard rate as well as the parameters $\mu_{R}, \gamma_{R}$ of the R\&D investment cost have been chosen such that expected innovation times in equilibrium are about 1 year. This seems to be in accordance with product development cycles in certain industries, like for instance the Laptop industry (see also Pacheco-de-Almeida 2010). In Appendix $\mathrm{C}$ we provide an extensive robustness analysis in which we demonstrate that the main qualitative findings presented in this paper continue to hold for a reasonable range of parameter values around the default setting.

\footnotetext{
${ }^{3}$ See for example Vedenov and Miranda (2001) and Dawid et al. (2015, 2017) for more details on the collocation method.
} 


\begin{tabular}{|l|l|l|l|}
\hline Symbol & Definition & Constraint & Baseline \\
\hline$\alpha$ & Effectiveness of current R\&D & $\geq 0$ & 0.2 \\
\hline$\beta$ & Effectiveness of past R\&D & $\geq 0$ & 0.2 \\
\hline$\psi$ & Marginal impact of past R\&D & $\geq 0$ & 2 \\
\hline$\eta$ & Horizontal differentiation & $|\eta|<1$ & 0.65 \\
\hline$\theta$ & Vertical differentiation & $\geq 0$ & 0.2 \\
\hline$\delta_{1}, \delta_{2}$ & Depr. rate for capacities $K_{1}, K_{2}$ & $>0$ & 0.2 \\
\hline$\delta_{R}$ & Organizational forgetting & $>0$ & 0.3 \\
\hline$\mu_{1}, \mu_{2}$ & Unit price of prod. capacity $i=1,2$ & $\geq 0$ & 0 \\
\hline$\mu_{R}$ & Unit price of knowledge capital & $\geq 0$ & 0.2 \\
\hline$\gamma_{1}$ & Adj. cost for product $i=1$ & $>0$ & 3 \\
\hline$\gamma_{2}$ & Adj. cost for product $i=2$ & $>0$ & 3 \\
\hline$\gamma_{R}$ & Adj. cost for knowledge capital & $>0$ & 0.1 \\
\hline$r$ & Interest rate & $0<r \leq 1$ & 0.04 \\
\hline
\end{tabular}

Table 1: Baseline Parameter Setting of the Model

Before examining the properties of the firms' optimal R\&D strategies in the following sections, we briefly illustrate the implications of differences in the initial capacity on the firms' dynamic investments in production capacities. The purpose is to show how the dynamics of firm sales is affected by the order and timing of the product innovations by the two firms. In Figure 1 we show the dynamics of production capacities in a situation where firms are symmetric except for the initial size of the production capacity on the established product market. ${ }^{4}$ Both firms start with zero R\&D knowledge, firm A's production capacity for the established product corresponds to the steady state level in a standard one-product capital accumulation game where firms do not account for the option to develop a new product, and firm B starts with half of firm A's production capacity. As discussed below, it turns out that the expected innovation time of the smaller firm B is shorter than that of its larger competitor A. Therefore, for the purpose of illustration it is assumed in Figure 1 that firm B enters the new market first. In panel (a) of Figure 1 it is assumed that innovation times of the incumbents equal their expected values (see Section 8). The figure highlights a strong path dependency on the established market: due to the innovation process, firm $B$ stays the smaller firm on that market for the entire time interval depicted although structurally the two firms are completely symmetric. Furthermore, it can be clearly seen that both firms reduce their capacities for the established product once the new submarket emerges, where the effect is much stronger for the innovator. In panel (b), later innovation times are assumed in order to show the full dynamics of the firms' production capacities which might emerge in each mode. Comparing the two panels of Figure 1 shows that the qualitative features of the firms' dynamic investment strategies do not depend on the actual times of the realizations of the innovations. Panel (b) also illustrates that, since the two firms are structurally symmetric they end up with symmetric capacities in the long run after both firms have entered the new submarket.

\footnotetext{
${ }^{4}$ Although, in general, we cannot expect uniqueness of Markov Perfect Equilibria of the considered game, we have always found only a single MPE in our numerical explorations. To ensure robustness, we have carried out the analysis for a wide range of initializations of the collocation algorithm without finding other MPEs. All figures show the trajectories resulting from this single MPE.
} 


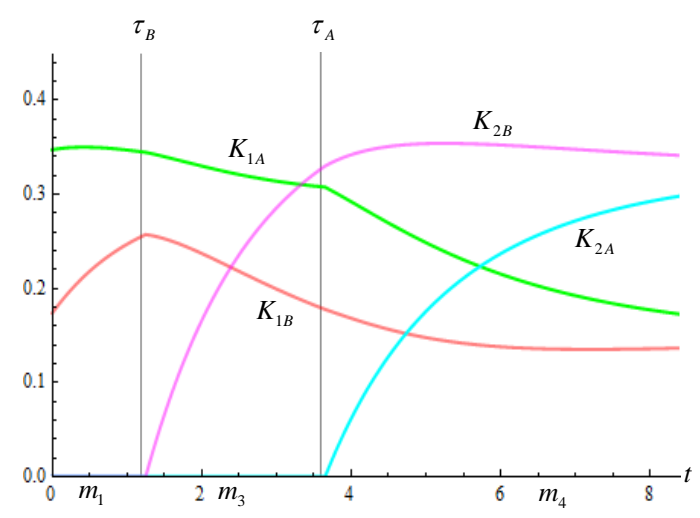

(a)

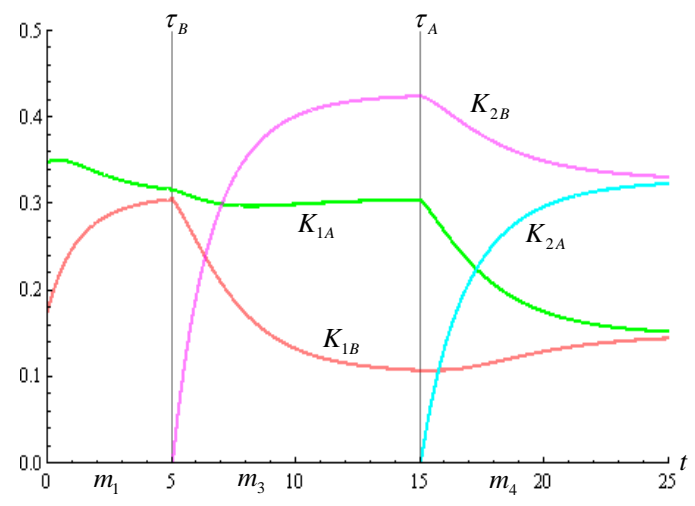

(b)

Figure 1: Equilibrium dynamics of production capacities for the established product and the new product for asymmetric initial capacities on the established market. In the scenario depicted the smaller firm B innovates first. In Panel (a) innovation times correspond to their expected values, in panel (b) innovation times are sufficiently large such that the (approximate) steady state in each mode is reached.

\section{$5 \quad$ Firm Size and Innovation Timing}

This paper argues that the observed pattern that large incumbent firms typically enter newly emerging submarkets later than their smaller rivals is fully consistent with long run profit maximization behavior. For this reason we study how an incumbent's size on the established market (in terms of production capacities) affects investment incentives and the timing of innovation. Figure 2 shows the evolution of the hazard rate for the scenario depicted in Figure 1. The initial difference in the incumbents' production capacities on the established market leads to a persistent difference in the firms' hazard rates in mode $m_{1}$. As shown, firm $\mathrm{B}$ with a smaller capacity on the established market has a higher hazard rate of innovation. The smaller incumbent has a higher incentive to innovate and thus has a smaller expected innovation time than the larger incumbent A.

The intuition for the observation that the smaller firm has a larger incentive to innovate is as follows. As discussed in the previous section and highlighted in (10) and (11), firms' investment in $R \& D$ knowledge stock is mainly driven by two effects: first, the marginal change in the value function of the current mode induced by an increase in the R\&D knowledge stock and, second, the jump in the value function caused by the innovation breakthrough and the associated creation of a new submarket. The size of the firm's production capacity on the established market mainly affects the second of these two effects. The reason is that the introduction of the new product in the new (but linked) submarket results in a decrease of the price for the established product and the firm with the larger capacity on the established market is more strongly affected by it. Hence, the difference between the firm's value function in the mode where the firm is the innovation leader (i.e. $m_{2}$ for firm $\mathrm{A}$ and $m_{3}$ for firm B) and the value function in mode $m_{1}$ is decreasing in the firm's production capacity on the established market.

Figure 3(a) shows the dependence of equilibrium investment in R\&D knowledge stock on the capacities on the established market. ${ }^{5}$ The figure reveals that the cannibalization effect indeed is an important force shaping the influence of a firm's engagement in the

\footnotetext{
${ }^{5}$ The range of capacities $K_{1 A}, K_{1 B}$ considered in the figure covers the whole interval between 0 and the monopoly output level on the established market.
} 


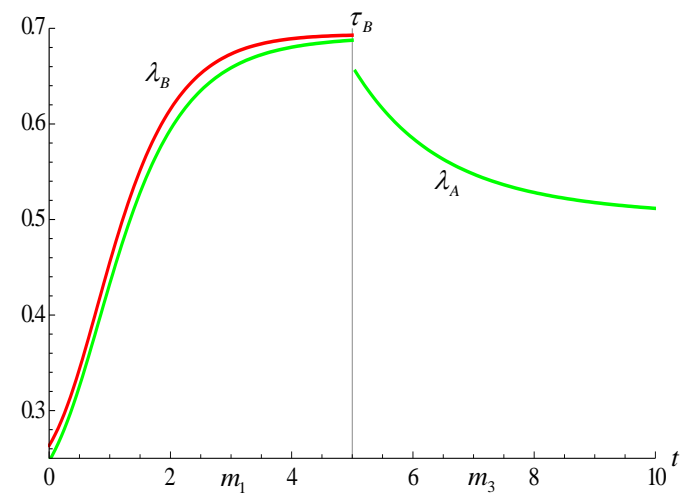

(a)

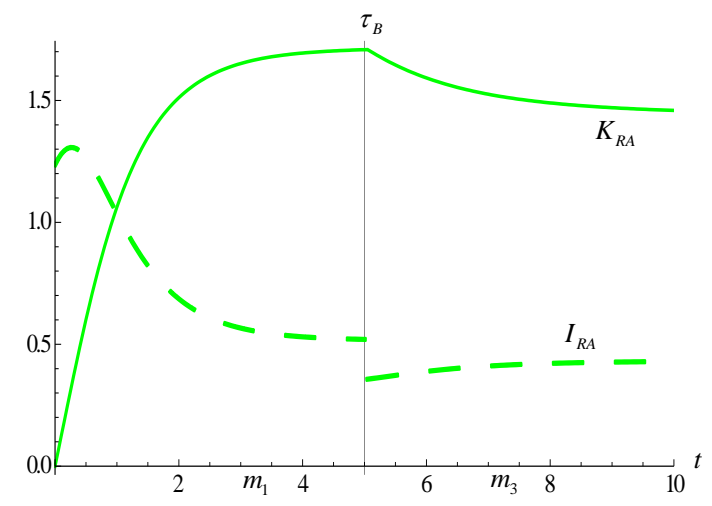

(b)

Figure 2: Equilibrium dynamics of the hazard rates for asymmetric initial production capacities on the established market. It is assumed that the smaller firm B innovates first.

established product market on a firm's incentive to invest in R\&D knowledge stock. Furthermore, the incentive to invest in R\&D knowledge stock is influenced by a size effect. As the figure highlights, a firm's investment in R\&D knowledge stock is also negatively affected by the competitor's size on the established market (although this dependence is weaker). The mechanism driving this relation is that a larger production capacity on the established market induces a smaller price for the new product after its introduction. This reduces the profitability of the new product and thereby the incentive to speed up the introduction of the new product. Note that, in contrast to the cannibalization effect, for the size effect it is irrelevant whether the expansion of the capacity on the established market is due to an increase of the competitor's production capacity or the firm's own production capacity. Overall, the capacities of both firms on the established market negatively influence the firm's incentive to invest in R\&D knowledge stock, but the effect of the firm's own capacity is much stronger. Taken together, the size and the cannibalization effect explain why the larger firm has a lower incentive to invest in R\&D knowledge stock and, consequently, has a larger expected innovation time.

Concerning the effect of the competitor's capacity, $K_{1 B}$, on a firm's investment in R\&D knowledge stock, $I_{R A}$, there is also an additional strategic $R \& D$ effect. This effect arises since the competitor's R\&D investment, $I_{R B}$, is negatively influenced by its production capacity $K_{1 B}$ on the established market. In turn, a lower level of investments $I_{R B}$ over time induces a reduction in the competitor's R\&D knowledge stock $K_{R B}$. Panel (b) of Figure 3 shows that there is a negative relationship between the R\&D knowledge stock of firm B and firm A's investment in its R\&D knowledge stock. Taken together, the strategic effect of an increase of the competitor's production capacity $K_{1 B}$ on firm A's investment in R\&D knowledge stock is positive. However, as Figure 3(a) demonstrates, this strategic effect is dominated by the direct effect (discussed above) of an increase of the competitor's capacity on a firm's investment in R\&D knowledge stock.

Figure 3(b) shows that besides the negative relation between the competitor's R\&D knowledge stock, $K_{R B}$, and firm A's investment in R\&D, $I_{R A}$, firm A's own R\&D knowledge stock, $K_{R A}$, negatively influences the firm's own level of investment in R\&D knowledge stock as well (in large parts of the state space). The intuition for both of these negative relationships is that larger $\mathrm{R} \& \mathrm{D}$ knowledge stocks reduce the expected duration of mode $m_{1}$. The transition to a different mode either strongly reduces (in case the com- 


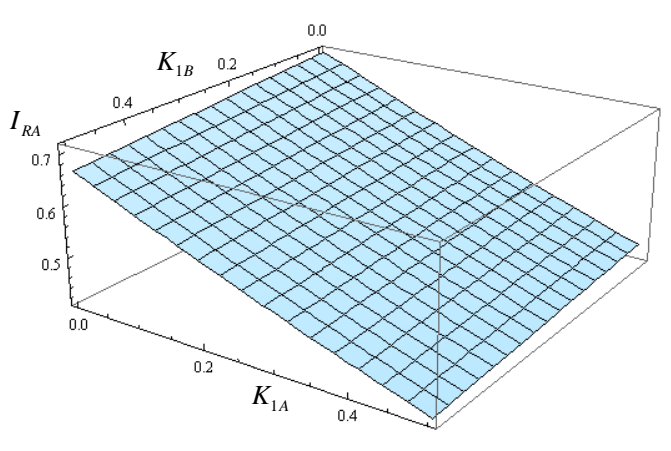

(a)

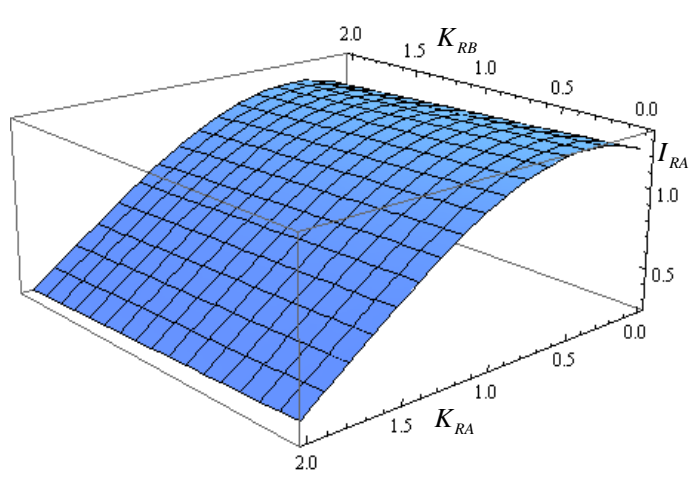

(b)

Figure 3: Investment in knowledge stock of firm A depending on production capacities on the established market (a) and R\&D knowledge stocks of the two firms (b). The values of the arguments of the feedback functions not varied are fixed at the steady state levels in mode $m_{1}$.

petitor is the innovator) or completely eliminates (if firm A itself is the innovator) the value of the firm's R\&D knowledge stock. Doraszelski (2003) identifies a similar effect in a patent race setting and denotes it as the 'pure knowledge effect'. For small values of $K_{R A}$ the convexity of the hazard rate with respect to a firm's own R\&D knowledge stock is the dominant force inducing a positive relationship between $K_{R A}$ and $I_{R A}$.

\section{Impact of Competitor's Innovation on R\&D Strategy}

The creation of the new submarket by a competitor has substantial implications for the optimal dynamic innovation strategy of the laggard. Figure 2(a) demonstrates that the hazard rate of firm A exhibits a downward jump at $t=\tau_{B}$ when the competitor's innovation project is successful and the new product is introduced to the submarket. This discontinuity is followed by a smooth decreasing pattern. A direct implication of this observation is that the expected waiting time until firm $A$ 's project is successfully finished exhibits an upward jump after the opponent's innovation and then actually keeps increasing. ${ }^{6}$

The expected value of introducing the new product decreases considerably at the time the competitor creates the new submarket. This is due to the fact that at this point the possibility to become temporarily the sole supplier of the new product, which is associated with a high profit, vanishes. For this reason, firm A's investments in R\&D knowledge stock drops at $t=\tau_{B}$ and so does the hazard rate. The reduction in the level of investments in $R \& D$ induces firm A's R\&D knowledge stock to decrease over time. Taking into account the pure knowledge effect, this decrease in $R \& D$ knowledge stock has a positive impact on the level of firm A's R\&D investments. Figure 2(b) demonstrates that this effect results in an increasing pattern of $I_{R A}$ in mode $m_{3}$ even though the quick build-up of capacity for the new product by firm $B$ further reduces the attractiveness of the innovation for firm $A$.

\footnotetext{
${ }^{6}$ With respect to this observation it should be noted that technological spillovers or imitation effects are not captured by our model. Such effects might make it easier for the laggard to develop the new product after the innovation leader has introduced it to the market. Here we focus strictly on the strategic implications of the opponent's product innovation.
} 


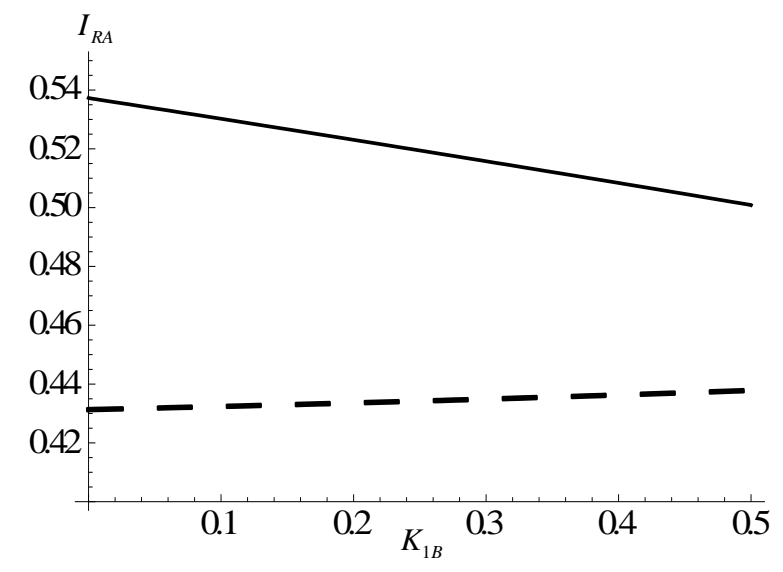

Figure 4: Investment in R\&D knowledge of firm A depending on capacities on the established market of firm B before (solid line) and after (dashed line) firm B has innovated.

The discussion above highlights that the laggard's level of investment in R\&D knowledge stock differs between modes $m_{1}$ and $m_{3}$. However, there are also qualitative changes in the properties of the innovation strategy. In particular, the transition from mode $m_{1}$ to $m_{3}$ implies that the sign of the relationship between investment in R\&D knowledge stock and the opponent's production capacity for the established market changes (see Figure 4). In mode $m_{1}$, an increase in incumbent B's production capacity $K_{1 B}$ decreases firm A's incentive to invest in $\mathrm{R} \& \mathrm{D}$ (bold line), whereas in mode $m_{3}$ it implies an increase in firm A's R\&D activities (dashed line). The reason for this qualitative change is that once firm $B$ is active on the new submarket, an increase of its production capacity on the established market induces a reduction of firm B's future investment on the new market. This, in turn, makes the new submarket more attractive for firm A and, therefore, results in an increase of firm A's investment in R\&D knowledge stock. Although this effect is already present in mode $m_{1}$, there the effect is weighted with the probability that the opponent wins the race and is discounted according to the expected innovation time. Hence, in mode $m_{1}$ this effect is dominated by the size effect and we observe the decreasing pattern as discussed above.

From a managerial perspective the main insight from this section is that it highlights how to adjust the innovation strategy once a competitor has successfully created a new submarket.

\section{Competitive Disadvantage as a Basis for Innovation Lead- ership}

Our analysis so far has assumed that the two competitors (only) possess different initial production capacities on the established market. In this context we have been studying the strategic implications of transitory differences for the $R \& D$ strategies of otherwise structurally identical firms. This section turns to the case where firms differ with respect to their competitiveness on the established market. In particular, we impose that investment costs of firm $B$ on the established market are higher than that of firm $A .^{7}$

\footnotetext{
${ }^{7}$ In the following numerical explorations we adjust our baseline parameter setting given in Table 1 by increasing the adjustment cost parameter of firm $B$ on the established market to $\gamma_{1 B}=9$, but keep firm
} 


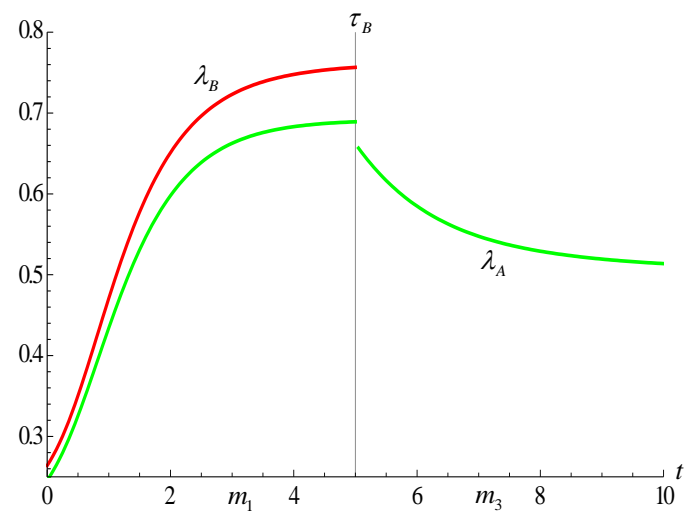

(a)

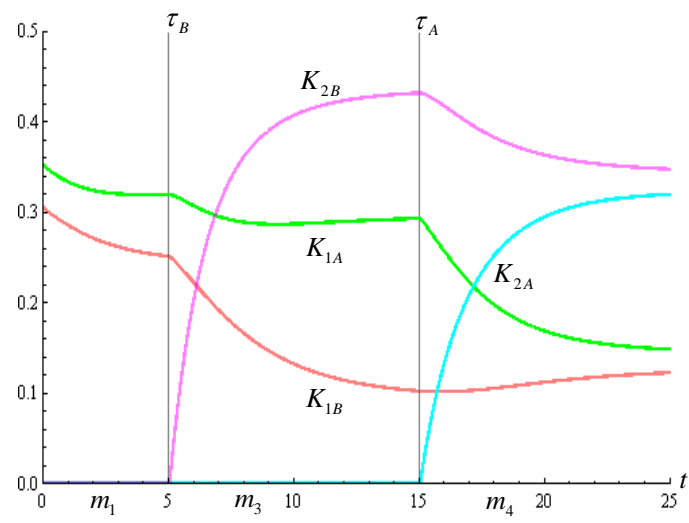

(b)

Figure 5: Hazard rates (a) and equilibrium dynamics of production capacities (b) in a scenario with asymmetric adjustment costs on the established market $\left(\gamma_{1 A}=3, \gamma_{1 B}=9\right)$.

The dynamics emerging in equilibrium in such a setting is depicted in Figure 5. Like in Figure 1, initial R\&D knowledge stocks of both firms are assumed to be zero. The initial production capacities on the established market correspond to the steady state values of this game without product innovation option. Due to its competitive disadvantage with respect to investment costs, the initial production capacity of firm $\mathrm{B}$ on the established market is, therefore, lower than firm A's capacity. The figure highlights two important implications of this structural asymmetry between firms. First, panel (a) reveals that throughout mode $m_{1}$ firm $\mathrm{B}$ has a larger hazard rate than firm A. This implies that firm $B$ has a smaller expected innovation time than firm A and a larger probability of winning the innovation race. Second, under the assumption that firm B innovates first, it has a strictly smaller production capacity on the established market, but a strictly larger production capacity on the new submarket throughout all modes where these markets exist (see panel (b)). Consequently, the disadvantage of higher investment costs on the established market acts as a commitment device for firm B to be more aggressive during the innovation race and also to be a tougher competitor on the new submarket. Innovation leadership then follows from the negative relationship between the firm's own capacity on the established market and its incentive to invest in R\&D knowledge stock, as discussed in Section 5.

The previous discussion shows that the disadvantage of firm B with respect to investment costs on the established market has two counteracting implications for the firm's profit. The direct effect is that the profit of firm B on the established market is negatively affected by its larger capital adjustment costs. The indirect effect is that firm A invests less in its $R \& D$ knowledge stock because firm A takes into account that firm $B$ has a stronger incentive to invest in $\mathrm{R} \& \mathrm{D}$. This raises firm B's profit. The second effect becomes more important if the expected time until the creation of the new submarket is shorter. In the framework of our model this aspect is closely related to the parameter $\alpha$, which measures the impact of R\&D investment on the breakthrough probability. Figure 6 illustrates that, for sufficiently large values of $\alpha$, the firm with a structural disadvantage on the established market can indeed have a larger expected discounted payoff than its more efficient competitor. ${ }^{8}$

A's adjustment cost parameter at $\gamma_{1 A}=3$.

${ }^{8}$ In order to isolate the effect of an asymmetry in capacity adjustment costs (represented by $\gamma_{1} f$ ) on the 


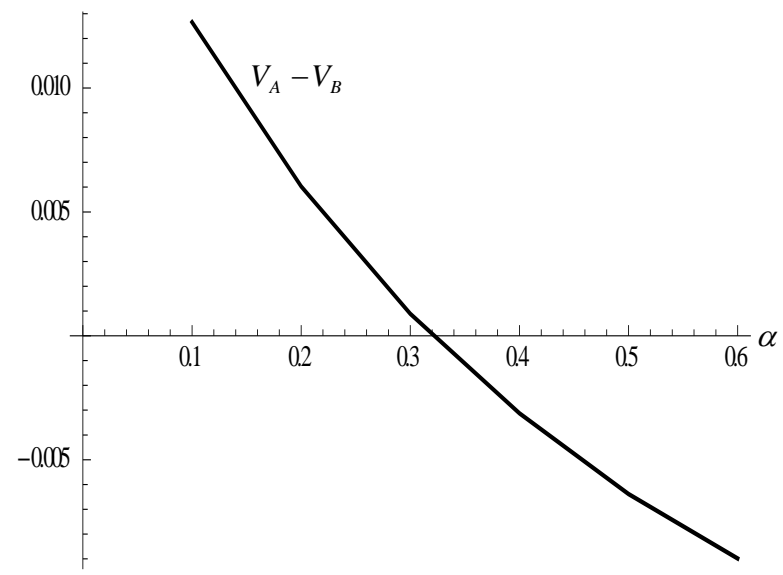

Figure 6: Difference in the value functions of firms A and B for different values of the parameter $\alpha$ and symmetric initial conditions.

\section{Competition and Speed of Innovation}

Our discussion in sections 5 and 6 has highlighted that each firm can induce a downward jump in the R\&D activities of its opponent by launching the new product and, even before that, can reduce the competitor's R\&D investments by increasing its own knowledge stock. This implies that in the duopoly setting competition induces additional incentives to undertake R\&D investment. ${ }^{9}$ Hence, from a managerial perspective, the question arises, how R\&D investments should be adjusted to the intensity of competition. To address this issue, in Figure 7 we compare the optimal R\&D strategies of firm A in our standard duopoly setting with the scenario in which it is a monopolist. ${ }^{10}$ The figure clearly shows that, regardless of the production capacity on the established market and the level of firm A's knowledge stock, it always invests more in R\&D if no competitor is on the market. The main driving force of this finding is that in a monopoly the innovator does not need to reckon with later entry of the competitor into the new submarket, so that the expected intertemporal rent is larger than in the duopoly. Put more formally, whereas in duopoly the value function of the innovator will eventually exhibit a downward jump when the other firm also launches the new product, under monopoly the innovator can extract the monopoly rent for the new product indefinitely.

Although the incentives to invest in $\mathrm{R} \& \mathrm{D}$ for the individual firm are larger in a monopoly market compared to duopoly, Figure 8 shows that nevertheless the speed of innovation is faster in duopoly. ${ }^{11}$ Despite the lower hazard rate for each individual firm,

value functions of firms $A$ and $B$, the difference in value functions in Figure 6 is calculated for symmetric initial conditions $K_{1 A}^{i n i}=K_{1 B}^{i n i}=0.353$. This value corresponds to the steady-state capacity of firm $A$ in the game without innovation option.

${ }^{9}$ In the literature this known as the 'Arrow replacement effect' (Arrow (1962)).

${ }^{10}$ More formally, we consider the dynamic optimization problem of firm A if firm B is absent from the established market and also cannot innovate, see Dawid et al. (2015) for a formal definition of the monopoly problem.

${ }^{11}$ To make the monopoly scenario comparable to the duopoly we assume that the initial production capacity of the monopolist on the established market is given by the sum of the initial production capacities by the two firms in the duopoly scenario. The expected values in this figure have been calculated for varying degrees of horizontal differentiation using Monte Carlo simulation of the dynamics emerging under the feedback strategies numerically determined by collocation methods for the different scenarios and our baseline parameter setting provided in Table 1. 


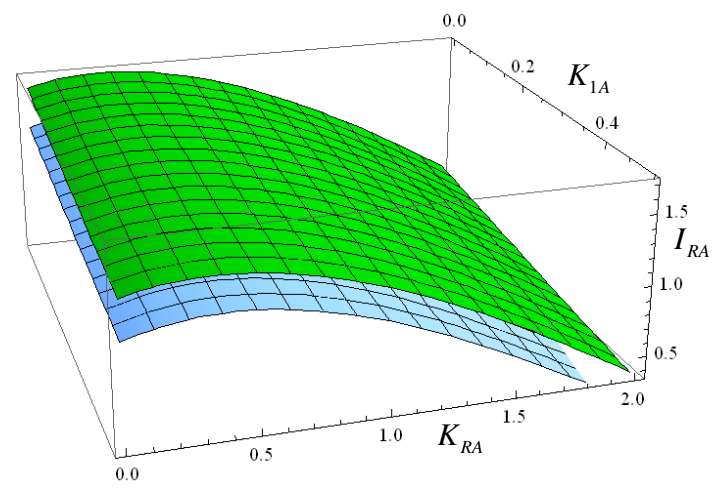

Figure 7: $\mathrm{R} \& \mathrm{D}$ investment of firm $\mathrm{A}$ as a monopolist (green) vs. a duopolist with the competitor's state variables being equal to the steady state of mode $m_{1}$ (blue).

the expected time until the creation of the new submarket is lower in duopoly, because both competitors are working independently to achieve the innovation breakthrough.

In Figure 8 we also compare the expected innovation times under the two considered market structures with the benchmark of the expected innovation time under a strategy profile that is optimal from a social planner perspective. ${ }^{12}$ It becomes clear that although competition speeds up innovation relative to a monopoly scenario, from a social planner perspective even faster innovation would be desirable. Intuitively, this is due to the fact that from the perspective of consumers, the creation of the new submarket generates a surplus which is not taken into account by the firms. Firms are not able to fully appropriate the returns of their investments in R\&D knowledge stock. Hence, expected innovation time is higher than in the social optimum.

\section{Conclusions}

In this paper we analyze which effects drive the incentives of incumbents to invest in the development of a resource - an R\&D knowledge stock - which enhances the likelihood that a product innovation can be introduced to a new submarket. Our dynamic setting particularly emphasizes the interplay between the incumbents' established product market and the new submarket by taking into account that the new product is a partial substitute for the established product. It also explicitly factors in that the adjustment of resources for production are costly and take time.

Our setting provides several important managerial insights about the optimal dynamic innovation strategies of incumbent firms. First, with regard to the empirically observed pattern that larger incumbents are often late to enter emerging new submarkets, we find that it is in fact the optimal strategy for an incumbent with a large production capacity on the established product to invest less in resources for the development of the new product. This result contrasts with earlier explanations that emphasize the benefits of an "eat your own lunch before someone else does" approach. It is, however, perfectly in line with more recent work which argues that leader firms may not always find it optimal to cannibalize their existing advantage (e.g. Pacheco-de-Almeida 2010). In other words,

\footnotetext{
${ }^{12} \mathrm{~A}$ formal definition of the social planner problem is given in Appendix D.
} 


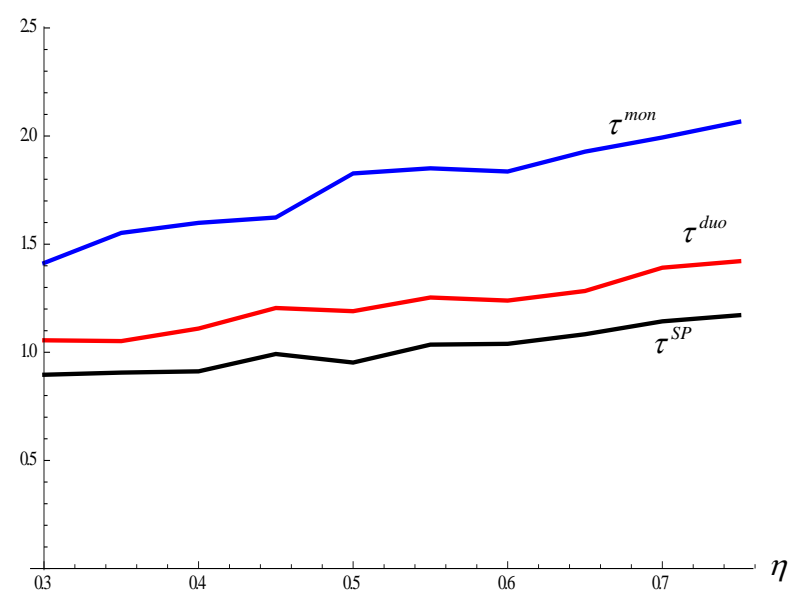

Figure 8: Expected time of the first innovation for different degrees of horizontal differentiation for duopoly (red), monopoly (blue), and the social planner problem (black).

our findings confirm that a larger incumbent might rationally accept a higher probability of being replaced by its smaller competitor which becomes the leader in the created new submarket. Second, we show that it is optimal for an incumbent to reduce its investment in resources for product innovation once the opponent has successfully launched its new product in the submarket. We further demonstrate that the optimal investment strategy to develop resources for product innovation differs qualitatively in the periods before the opponent's product innovation and after the opponent has successfully entered the new submarket. Our third finding addresses the impact of a firm's structural disadvantage, that is captured by higher costs of adjusting production capacity for the established product, on the firm's incentive to invest in R\&D knowledge. What we find is that such a competitive disadvantage can actually turn out to be beneficial in the innovation race in the long run as it acts as a commitment device for the disadvantaged firm to invest more aggressively in the development of resources that are essential for a product innovation. We identify scenarios where this effect can be so substantial that despite the higher capacity adjustment costs on the established market, the cost follower can end up with a higher overall expected discounted profit than the more efficient cost leader.

From a normative point of view, these insights are important to benchmark optimal innovation strategies of established firms that compete in product R\&D in oligopoly markets and face the problem of how to determine the optimal investment strategy in resources for established and newly developed products in their product lines. From a policy perspective, our analysis shows that competition between two incumbent firms reduces the time until a new product is introduced and brings it closer to the socially optimal level. Furthermore, our results might provide a theoretical basis for empirical studies that analyze the effect of the (relative) market share of firms on established markets on the (relative) level of investment in product innovation, or the effect of new product launches by opponents on a firm's investment in product innovation.

The analysis in this paper is restricted to scenarios where the new product launched by incumbent firms in a newly created submarket is a (partial) substitute of the incumbents' established product. Although in most industries this seems to be the more relevant case, our model can also be employed to study the properties of the optimal intertemporal innovation strategies if incumbents invest in the development of new products which are 
complements of their current product. Our findings for the case of complementary products indicate that the qualitative results about the monotonicity of the investment in R\&D knowledge stock with respect to production capacities for the established product of a firm and its competitor are reversed. However, similar to the substitutes case considered in this paper, the creation of the new submarket by a competitor induces a downward jump in the firm's innovation activities if the new product is a complement to the established product.

A limitation we share with most of the literature on innovation incentives under oligopolistic competition is that firms do not face any financial constraints. As a consequence, firms are always able to fully implement their planned investment strategies. However, a rich empirical literature indicates that many firms encounter difficulties in obtaining external funding for investments in $\mathrm{R} \& \mathrm{D}$, and, therefore, have to rely on internal sources for financing their R\&D activities. This opens up an additional channel which influences the interaction between a firm's accumulated profits resulting from established products and a firm's incentive to invest in product innovation. Examining the impact of financial constraints and internal funding of R\&D activities on the firm's optimal dynamic innovation strategy is a challenging avenue for future research.

\section{References}

Adner, R. and P. Zemsky (2005), Disruptive Technologies and the Emergence of Competition, Rand Journal of Economics, 36, 229-254.

Adner, R. and P. Zemsky (2006), A Demand-Based Perspective on Sustainable Competitive Advantage, Strategic Management Journal, 27, 215-239.

Anand, K.S. and K. Girotra (2007), The Strategic Perils of Delayed Differentiation, Management Science, 53, 697-712.

Arrow, K. (1962), Economic Welfare and the Allocation of the Resources for Invention, in Nelson, R.R. (Ed.): The Rate and Direction of Inventive Activity, Princeton University Press, pp. 609-627.

Besanko, D., Doraszelski, U. (2004), Capacity Dynamics and Endogenous Asymmetries in Firm Size, The RAND Journal of Economics, 35, 23-49.

Besanko, D., U. Doraszelski, L. X. Lu, and M. Satterthwaite (2010), Lumpy Capacity Investment and Disinvestment Dynamics, Operations Research, 58, 1178-1193.

Buensdorf, G. (2016), Schumpeterian Incumbents and Industry Evolution, Journal of Evolutionary Economics, 26, 823-836.

Bresnahan, T.F., S. Greenstein, R. M. Henderson (2012), Schumpeterian Competition and Diseconomies of Scope: Illustrations from the Histories of Microsoft and IBM, in Lerner, J. and Stern, S. (Eds.): The Rate and Direction of Inventive Activity Revisited, Oxford University Press, pp. 203-271.

Breton, M., Vencatachellum, D. and G. Zaccour (2006), Dynamic R\&D with Strategic Behavior, Computers and Operations Research 33, 426-437.

Casadesus-Masanell, R. and D. B. Yoffie (2007), Wintel: Cooperation and Conflict, Management Science, 53, 584-598.

Casadesus-Masanell, R. and P. Ghemawat (2006), Dynamic Mixed Duopoly: A Model Motivated by Linux vs. Windows, Management Science, 52, 1072-1084. 
Cellini, R. and L. Lambertini (2002), A Differential Game Approach to Investment in Product Differentiation, Journal of Economic Dynamics and Control, 27(1), 51-62.

Cellini, R. and L. Lambertini (2009), Dynamic R\&D with Spillovers: Competition vs. Cooperation, Journal of Economic Dynamics and Control, 33, 568-582.

Chandy, R.K. and G.J. Tellis (2000), The Incumbent's Curse? Incumbency, Size, and Radical Product Innovation, Journal of Marketing, 64, 1-17.

Christensen, C., The Innovator's Dilemma, Harvard Business School Press, Boston, 1997.

Dawid, H., Kopel, M. and P.M. Kort (2013), New Product Introduction and Capacity Investment by Incumbents: Effects of Size on Strategy, European Journal of Operational Research, 230, 133-142.

Dawid, H., Keoula, M.Y., Kopel, M. and P.M. Kort (2015), Product Innovation Incentives by an Incumbent Firm: A Dynamic Analysis, Journal of Economic Behavior and Organization, 117, 411-438.

Dawid H., Keoula M.Y., Kort P.M. (2017), Numerical Analysis of Markov-Perfect Equilibria with Multiple Stable Steady States: A Duopoly Application with Innovative Firms, forthcoming in Dynamic Games and Applications.

Desai, P.S. (2001), Quality Segmentation in Spatial Markets: When Does Cannibalization Affect Product Line Design? Marketing Science, 20, 265-283.

Dierickx, I. and K. Cool (1989), Asset Stock Accumulation and Sustainability of Competitive Advantage, Management Science, 35, 1504-1511.

Dockner, E.J., Jorgensen, S., Van Long, N. and G. Sorger (2000), Differential Games in Economics and Management Science, Cambridge University Press, Cambridge.

Doraszelski, U. (2003), An R\&D Race with Knowledge Accumulation", RAND Journal of Economics, 34 19-41.

Doraszelski, U. and A. Pakes (2007), A Framework for Applied Dynamic Analysis in IO, in Armstrong, M. and Porter, R. (Eds.): Handbook of Industrial Organization, Vol. 3, pp. 1887-1966.

Dosi, G. (1988), Sources, Procedures and Microeconomic Effects of Innovation, Journal of Economic Literature, XXVI, 1120-1171.

Escobar, J.F. (2013), Equilibrium Analysis of Dynamic Models of Imperfect Competition, International Journal of Industrial Organization, 31, 92-101.

Franco, A.M., Sarkar, M.B., Agarwal, R. and R. Echambadi (2009), Swift and Smart: The Moderating Effects of Technological Capabilities on the Market Pioneering-Firm Survival Relationship. Management Science, 55, 1842-1860.

Ghemawat, P. and B. Cassiman (2007), Introduction to the Special Issue on Strategic Dynamics, Management Science, 53, 529-536.

Goyal, M. and S. Netessine (2007), Strategic Technology Choice and Capacity Investment under Demand Uncertainty, Management Science, 53, 192-207.

Henderson, R. (1993), Underinvestment and Incompetence As Responses to Radical Innovation: Evidence from the Photolithographic Alignment Equipment Industry, RAND Journal of Economics, 24, 248-270.

Henderson, R. M. (2006), The Innovator's Dilemma as a Problem of Organizational Com- 
petence, Journal of Product Innovation Management, 23, 5-11.

Huang, X. and G. Sosic (2010), Analysis of Industry Equilibria in Models With Sustaining and Disruptive Technology, European Journal or Operational Research, 207, 238-248.

Huisman, K.J.M. and P.M. Kort (2015), Strategic Capacity Investment under Uncertainty, The RAND Journal of Economics, 46, 376-408.

Jun, B. and X. Vives (2004), Strategic Incentives in Dynamic Duopoly, Journal of Economic Theory, 116, 249-281.

Judd, K.L., Maliar, L., Maliar, S. and R. Valero (2014), Smolyak Method for Solving Dynamic Economic Models: Lagrange Interpolation, Anisotropic Grid and Adaptive Domain, Journal of Economic Dynamics and Control, 44, 92-123.

King, A.A. and C.L. Tucci (2002), Incumbent Entry into New Market Niches: The Role of Experience and Managerial Choice in the Creation of Dynamic Capabilities, Management Science, 48, 171-186.

Lambertini, L. and A. Mantovani (2009), Process and Product Innovation by a Multiproduct Monopolist: A Dynamic Approach, International Journal of Industrial Organization, 27, 508-518.

Lapham, B. and R. Ware (1994), Markov Puppy Dogs and Related Animals, International Journal of Industrial Organization, 12, 569-593.

Lus, B. and A. Muriel (2009), Measuring the Impact of Increased Product Substitution on Pricing and Capacity Decisions Under Linear Demand Models, Production and Operations Management, 18, 95-113.

Malin, B., Krueger, D. and F. Kubler (2011), Solving the Multi-country Real Business Cycle Model Using a Smolyak Collocation Method, Journal of Economic Dynamics and Control, 35, 229-239.

Maliar, L. and S. Maliar (2014), Numerical Methods for Large Scale Dynamic Economic Models, in Schmedders, K. and K. Judd (Eds.): Handbook of Computational Economics, Volume 3, Amsterdam: Elsevier Science, pp. 325-477.

Mitchell, M. and A. Skrzypacz (2015), A Theory of Market Pioneers, Dynamic Capabilities, and Industry Evolution, Management Science, 61, 1598-1614.

Moorthy, K.S. and I. P. L. Png (1992), Market Segmentation, Cannibalization, and the Timing of Product Introductions, Management Science, 38, 345-359.

Nault, B.R. and M. B. Vandenbosch (1996), Eating Your Own Lunch: Protection Through Preemption, Organization Science, 7, 342-358.

Ofek, E. and M. Sarvary (2003), R\&D, Marketing, and the Success of Next-Generation Products, Marketing Science, 22, 355-370.

Pacheco-de-Almeida, G. (2010), Erosion, Time Compression, and Self-Displacement of Leaders in Hypercompetitive Environments, Strategic Management Journal, 31, 14981526 .

Pacheco-de-Almeida, G. and P. Zemsky (2007), The Timing of Resource Development and Sustainable Competitive Advantage, Management Science, 53, 651-666.

Schmidt, G.M. and E.L. Porteus (2000a), The Impact of an Integrated Marketing and Manufacturing Innovation, Manufacturing \& Service Operations Management, 2, 317-336. 
Schmidt, G.M. and E. L. Porteus (2000b), Sustaining Technology Leadership Can Require Both Cost Competence and Innovative Competence, Manufacturing and Service Operations Management, 2, 1-18.

Sood, A. and R.J. Tellis (2011), Demystifying Disruption: A New Model for Understanding and Predicting Disruptive Technologies, Marketing Science, 30, 339-354.

Sterman, J.D., R. Henderson, E. D. Beinhocker, and L. I. Newman (2007), Getting Big Too Fast: Strategic Dynamics with Increasing Returns and Bounded Rationality, Management Science, 53, 683-696.

Swinney, R., G. P. Cachon, S. Netessine (2011), Capacity Investment Timing by Start-ups and Established Firms in New Markets, Management Science, 57, 763-777.

Tripsas, M. (1997), Unraveling the Process of Creative Destruction: Complementary Assets and Incumbent Survival in the Typesetter Industry, Strategic Management Journal, $18,119-142$.

Tripsas, M. and G. Gavetti (2000), Capabilities, Cognition, and Inertia: Evidence from Digital Imaging, Strategic Management Journal, 21, 1147-1161.

Vedenov, D.V. and M.J. Miranda (2001), Numerical Solution of Dynamic Oligopoly Games with Capital Investment, Economic Theory, 18, 237-261.

Wu, B. Z. Wand, and D. A. Levinthal (2014), Complementary Assets as Pipes and Prisms: Innovation Incentives and Trajectory Choices, Strategic Management Journal, 35, 12571278.

Yayla-Küllü, H. M., A. K. Parlaktürk, J. M. Swaminathan (2013), Multi-Product Quality Competition: Impact of Resource Constraints, Productions and Operations Management, 22, 603-614.

Zenger, T.R. (1994), "Explaining Organizational Diseconomies of Scale in R\&D: Agency Problems and the Allocation of Engineering Talent, Ideas, and Effort by Firm Size", Management Science, 40, 708-729. 


\section{Appendices}

\section{Appendix A: Proof of Proposition 1}

Standard theory for piecewise deterministic games establishes that in each mode the value function of each firm in a Markov Perfect Equilibrium is characterized by a HamiltonJacobi-Bellman (HJB) equation. In particular we obtain the following HJB equations in the different modes (see Dockner et al. (2000)):

Mode $\mathbf{m}_{1}$ : the HJB equations of both firms are symmetric and are given by

$$
\begin{array}{r}
r V_{f}\left(K_{1 f}, K_{R f}, K_{1(-f)}, K_{R(-f)}, m_{1}\right) \\
=\max _{I_{1 f}, I_{R f}}\left[\left(1-\left(K_{1 A}+K_{1 B}\right)\right) K_{1 f}-\mu_{1 f} I_{1 f}-\frac{\gamma_{1}}{2} I_{1 f}^{2}-\mu_{R f} I_{R f}-\frac{\gamma_{R}}{2} I_{R f}^{2}\right. \\
+\frac{\partial V_{f}\left(\cdot, m_{1}\right)}{\partial K_{1 f}}\left(I_{1 f}-\delta K_{1 f}\right)+\frac{\partial V_{f,\left(m_{1}\right)}}{\partial K_{R f}}\left(I_{R f}-\delta_{R} K_{R f}\right) \\
+\frac{\partial V_{f}\left(\cdot, m_{1}\right)}{\partial K_{1(-f)}}\left(\phi_{1(-f)}-\delta K_{1(-f)}\right)+\frac{\partial V_{f,\left(m_{1}\right)}}{\partial K_{R(-f)}\left(\phi_{R(-f)}-\delta_{R} K_{R(-f)}\right)} \\
+\left(\alpha I_{R f}+\beta K_{R f}^{\psi}\right)\left(V_{f}\left(\cdot, m_{2}\right)-V_{f}\left(\cdot, m_{1}\right)\right) \\
\left.+\left(\alpha \phi_{R(-f)}+\beta K_{R(-f)}^{\psi}\right)\left(V_{f}\left(\cdot, m_{3}\right)-V_{f}\left(\cdot, m_{1}\right)\right)\right] .
\end{array}
$$

The last two terms on the right hand side of the HJB-equation have to be added to capture the effect of the future jump either to mode $m_{2}$ or mode $m_{3}$ on the value function in mode $m_{1}$. The right hand side (RHS) of equation (13) is strictly concave in $\left(I_{1 f}, I_{R f}\right)$. Consequently, the first order conditions for the maximization of the RHS are necessary and sufficient and yield expressions (9), (10) and (11) for $I_{1 f}$ and $I_{R f}$.

Mode $\mathbf{m}_{2}$ : in modes $m_{2}$ (and $m_{3}$ ) the HJB equations of the innovator and the laggard differ substantially. In mode $m_{2}$, the HJB equation of the innovator firm A reads

$$
\begin{aligned}
r V_{A}\left(K_{1 A}, K_{2 A}, K_{1 B}, K_{R B}, m_{2}\right) \\
=\max _{I_{1 A}, I_{2 A}}\left[\left(1-\left(K_{1 A}+K_{1 B}\right)-\eta K_{2 A}\right) K_{1 A}-\mu_{1 A} I_{1 A}-\frac{\gamma}{2} I_{1 A}^{2}\right. \\
+\left(1+\theta-K_{2 A}-\eta\left(K_{1 A}+K_{1 B}\right)\right) K_{2 A}-\mu_{2 A} I_{2 A}-\frac{\gamma}{2} I_{2 A}^{2} \\
+\frac{\partial V_{A}\left(\cdot, m_{2}\right)}{\partial K_{1 A}}\left(I_{1 A}-\delta K_{1 A}\right)+\frac{\partial V_{A}\left(\cdot, m_{2}\right)}{\partial K_{1 B}}\left(\phi_{1 B}-\delta K_{1 B}\right) \\
+\frac{\partial V_{A}\left(\cdot, m_{2}\right)}{\partial K_{2 A}}\left(I_{2 A}-\delta K_{2 A}\right)+\frac{\partial V_{A}\left(\cdot, m_{2}\right)}{\partial K_{R B}}\left(\phi_{R B}-\delta_{R} K_{R B}\right) \\
\left.\quad+\left(\alpha \phi_{R B}+\beta K_{R B}^{\psi}\right)\left(V_{A}\left(\cdot, m_{4}\right)-V_{A}\left(\cdot, m_{2}\right)\right)\right] .
\end{aligned}
$$


For the laggard firm B we obtain

$$
\begin{aligned}
r V_{B}\left(K_{1 A}, K_{2 A}, K_{1 B}, K_{R B}, m_{2}\right) & \\
=\max _{I_{1 B}, I_{R B}}\left[K_{1 B}(1-\right. & \left.\left(K_{1 A}(t)+K_{1 B}\right)-\eta K_{2 A}\right)-\mu_{1 B} I_{1 B}-\frac{1}{2} \gamma_{1} I_{1 B}^{2}-\mu_{R B} I_{R B} \\
-\frac{1}{2} \gamma_{R} I_{R B}^{2}+ & \frac{\partial V_{B}\left(\cdot, m_{2}\right)}{\partial K_{1 B}}\left(I_{1 B}-\delta_{1} K_{1 B}\right)+\frac{\partial V_{B}\left(\cdot, m_{2}\right)}{\partial K_{R B}}\left(I_{R B}-\delta_{R} K_{R B}\right) \\
& +\frac{\partial V_{B}\left(\cdot, m_{2}\right)}{\partial K_{1 A}}\left(\phi_{1 A}-\delta_{1} K_{1 A}\right)+\frac{\partial V_{B}\left(\cdot, m_{2}\right)}{\partial K_{2 A}}\left(\phi_{2 A}-\delta_{2} K_{2 A}\right) \\
& \left.+\left(\alpha I_{R B}+\beta K_{R B}^{\psi}\right)\left(V_{B}\left(\cdot, m_{4}\right)-V_{B}\left(\cdot, m_{2}\right)\right)\right] .
\end{aligned}
$$

In this mode, the last term captures the effect of the future jump to mode $m_{4}$ on the current value function.

Like in mode $m_{1}$, the derivation of the expressions of the investment functions (9) and (12) by the first order conditions is straightforward.

Symmetric equations are obtained for mode $m_{3}$, where firm B is the innovator and firm A is the laggard.

Mode $\mathbf{m}_{4}$ : in this mode the HJB equations are again symmetric across firms and read

$$
\begin{array}{r}
r V_{f}\left(K_{1 f}, K_{(2 f)}, K_{1(-f)}, K_{2(-f)}, m_{4}\right) \\
=\quad \max _{I_{1 f}, I_{2 f}}\left[K_{1 f}\left(1-\left(K_{1 A}+K_{1 B}\right)-\eta\left(K_{2 A}+K_{2 B}\right)\right)-\mu_{1 f} I_{1 f}-\frac{1}{2} \gamma_{1} I_{1 f}^{2}\right. \\
+K_{2 f}\left(1+\theta-\eta\left(K_{1 A}+K_{1 B}\right)-\left(K_{2 A}(t)+K_{2 B}\right)\right)-\mu_{2 f} I_{2 f}-\frac{1}{2} \gamma_{2} I_{2 f}^{2} \\
\quad+\frac{\partial V_{f}\left(\cdot, m_{4}\right)}{\partial K_{1 f}}\left(I_{1 f}-\delta_{1} K_{1 f}\right)+\frac{\partial V_{f}\left(\cdot, m_{4}\right)}{\partial K_{2 f}}\left(I_{2 f}-\delta_{2} K_{2 f}\right) \\
\left.+\frac{\partial V_{f}\left(\cdot, m_{4}\right)}{\partial K_{1(-f)}}\left(\phi_{1(-f)}-\delta_{1} K_{1(-f)}\right)+\frac{\partial V_{f}\left(\cdot, m_{4}\right)}{\partial K_{2(-f)}}\left(\phi_{2(-f)}-\delta_{2} K_{2(-f)}\right)\right]
\end{array}
$$

By the strict concavity of the RHS in $\left(I_{1 f}, I_{2 f}\right)$, the first order conditions are necessary and sufficient and again yield the expressions (9) for the investment functions.

\section{Appendix B: Numerical Solution of the Hamilton-Jacobi-Bellman Equa- tions}

In mode $m_{4}$, the game is a standard symmetric linear quadratic capital accumulation problem. Hence, the firms' value functions and also the HJB equations are symmetric and it is sufficient to solve for one value function. To this end, one postulates a quadratic form of the value function and inserts the resulting terms for the value function, its derivative and the induced feedback strategies into the HJB equation. Applying then the method of equating the coefficients of all orders of the state variables on both sides of the HJB equation yields a system of 14 quadratic algebraic equations. The system can be solved numerically by equation solvers to determine the 14 coefficients of the value function of the two firms for each constellation of parameters.

Since they have been derived from quadratic value functions, the above investment functions are linear on the state space $\left(K_{1 A}, K_{2 A}, K_{1 B}, K_{2 B}\right)$. Hence, the state dynamics is linear as well. In addition, one checks the transversality conditions $\lim _{t \rightarrow+\infty} e^{-r t} V_{A}\left(\cdot, m_{4}\right)(t)=$ 
0 and $\lim _{t \rightarrow+\infty} e^{-r t} V_{B}\left(\cdot, m_{4}\right)(t)=0$ by verifying that the trajectories induced by the investment functions are non-explosive. To that end, it is sufficient to check that the four eigenvalues of the Jacobian of the corresponding dynamical system are negative.

In mode $m_{1}$, the first step of the numerical scheme is the generation of a set of Chebychev nodes for each dimension (respectively $n_{1 f}, n_{R f}, n_{1(-f)}, n_{R(-f)}$ nodes in the considered state space) and a set of base-functions chosen as multi-variate Chebychev polynomials. The idea of the collocation method is to calculate an approximation of the value function by determining a weighted sum of the base functions such that the HJB equations are (approximately) satisfied on the set of nodes (see Dawid et al. (2017) for a more detailed description). In the standard approach the set of multivariate base function and the nodes are given by the tensor product of the uni-variate or one-dimensional Chebychev bases. However, due to the dimension of the state space in our problem this approach has proven ineffective with respect to computational effort and convergence properties of the collocation scheme.

Hence, our analysis relies on Smolyak collocation, which is a sparse grid method used to approximate solutions to the Hamilton-Jacobi-Bellman (HJB) equations for large scale dynamic economic systems subject to the curse of dimensionality. The method consists of selecting collocation nodes and associated polynomials by a non-tensor product rule that guarantees accuracy in spite of considering only a small subset of nodes and base functions resulting from the tensor product (see e.g. Maliar and Maliar (2014), Judd et al. (2014) and Malin et al. (2011) for a presentation of the Smolyak collocation method). The cardinality of the Smolyak grid is a polynomial function of the number of nodes in each dimension, compared to the exponential function that is called for by the tensor product. For example, for 5 nodes on each dimension and precision degree 5 , the cardinality of the Smolyak grid is 41. For 9 nodes and precision degree 3, the cardinality of the Smolyak grid is 137 . The traditional tensor product rules would have left us, respectively, with 625 and 6561 nodes.

In our numerical analysis Smolyak collocation has proven efficient and computationally feasible for the entire range of considered parameter constellations. Accuracy of the numerical approximations has been checked by considering the maximal (absolute) deviation of the right and the left hand side of the HJB equations (relative to the value function) on the entire state space. For the numerical results reported in this paper this error is always below $5 * 10^{-4}$.

\section{Appendix C: Robustness}

In this Appendix we identify intervals around the default values of the model parameters for which all the qualitative properties of the $R \& D$ investment functions identified in Sections 5 to 7 hold. In order to carry out these robustness tests, each considered parameter has been varied in the given interval and the changes in the value functions corresponding to these parameter variations have been calculated using homotopy methods. The analysis is based on the consideration of the properties of the MPE feedback functions associated with these value functions at the steady states in the corresponding modes. In Table 2 we give a verbal and formal description of the properties that we have checked. To account for potential numerical errors stemming from our method a margin of $5 \cdot 10^{-4}$ has been used to check for the signs of the involved expressions.

The following Table 3 gives the intervals of the key model parameters for which it has been checked that all the key properties listed in Table 2 hold. Even outside these ranges most properties seem very robust. The main reasons that the whole list of properties could 


\begin{tabular}{|l|l|l|l|}
\hline $\begin{array}{l}\text { Sub- } \\
\text { section }\end{array}$ & Mode & Description & Formal Criterium \\
\hline 5 & $m_{1}$ & $\begin{array}{l}\text { R\&D investment decreases w.r.t. } \\
\text { own old market capacity }\end{array}$ & $\frac{\partial \phi_{R A}\left(. ; m_{1}\right)}{\partial K_{1 A}}<-5.10^{-4}$ \\
\hline 5 & $m_{1}$ & $\begin{array}{l}\text { R\&D investment decreases w.r.t. } \\
\text { competitor's old market capacity }\end{array}$ & $\frac{\partial \phi_{R A}\left(\cdot ; m_{1}\right)}{\partial K_{1 B}}<-5.10^{-4}$ \\
\hline 5 & $m_{1}$ & $\begin{array}{l}\text { negative effect of own old market capacity } \\
\text { on R\&D is stronger than that of competitor's } \\
\text { capacity } \Rightarrow \text { larger firm invests less in R\&D) }\end{array}$ & $\begin{array}{l}\left|\frac{\partial \phi_{R A}\left(. ; m_{1}\right)}{\partial K_{1 A}}\right| /\left|\frac{\partial \phi_{R A}\left(. ; m_{1}\right)}{\partial K_{1 B}}\right| \\
>1+5.10^{-4}\end{array}$ \\
\hline 6 & $m_{3}$ & $\begin{array}{l}\text { R\&D investment increases w.r.t. } \\
\text { competitor's old market capacity after } \\
\text { opponent's innovation }\end{array}$ & $\frac{\partial \phi_{R A}\left(. ; m_{3}\right)}{\partial K_{1 B}}>5.10^{-4}$ \\
\hline 6 & $m_{1}, m_{3}$ & $\begin{array}{l}\text { R\&D investment exhibits a downward jump } \\
\text { when competitor innovates }\end{array}$ & $\phi_{R A}\left(. ; m_{1}\right)>\phi_{R A}\left(. ; m_{3}\right)$ \\
\hline
\end{tabular}

Table 2: Qualitative properties checked in the robustness analysis.

\begin{tabular}{|l|l|l|l|}
\hline Symbol & Definition & Baseline & Robust interval \\
\hline$\alpha$ & Effectiveness of current R\&D & 0.2 & {$[0.01,0.29]$} \\
\hline$\beta$ & Effectiveness of knowledge stock & 0.2 & {$[0.01,0.39]$} \\
\hline$\eta$ & Horizontal differentiation & 0.65 & {$[0.09,0.77]$} \\
\hline$\theta$ & Vertical differentiation & 0.2 & {$[0.16,0.32]$} \\
\hline$\mu_{R}$ & Unit costs of knowledge cap. & 0.2 & {$[0.06,0.23]$} \\
\hline$\gamma_{1}$ & Adjustment cost for prod. 1 & 3 & {$[1.16,4.38]$} \\
\hline$\gamma_{2}$ & Adjustment cost for prod. 2 & 3 & {$[0.34,4.87]$} \\
\hline$\gamma_{R}$ & Adjustment cost for knowledge cap. & 0.1 & {$[0.06,0.48]$} \\
\hline
\end{tabular}

Table 3: Range of parameter values where all qualitative properties listed in Table 2 are satsified.

not be verified outside the given intervals is that either the slope of the R\&D investment of firm B with respect to $K_{1 A}$ after the opponent's innovation (i.e. in mode $m_{3}$ ) is no longer positive but becomes slightly negative or that due to numerical issues the homotopy could not be extended beyond the considered parameter interval.

\section{Appendix D: The Social Planner Problem}

To define the social planner problem we note that the linear inverse demand system (5),(6) can be derived from the utility maximization of a representative consumer with a quadratic utility function of the form

$$
\begin{aligned}
U\left(K_{1 A}, K_{1 B}, K_{2 A}, K_{2 B}\right)= & \left(K_{1 A}+K_{1 A}\right)-\frac{1}{2}\left(K_{1 A}+K_{1 B}\right)^{2}-\eta\left(K_{1 A}+K_{1 B}\right)\left(K_{2 A}+K_{2 B}\right) \\
& +(1+\theta)\left(K_{2 A}+K_{2 A}\right)-\frac{1}{2}\left(K_{2 A}+K_{2 A}\right)^{2} .
\end{aligned}
$$

In mode $m_{2}\left(m_{3}\right)$ the capacity $K_{2 B}\left(K_{2 A}\right)$ has to be zero and for mode $m_{1}$, both $K_{2 A}$ and $K_{2 B}$ are zero. Taking into account that production costs have been normalized to zero and assuming the same discount rate as in the firms' problem we can therefore write the 
welfare function for an arbitrary profile of investment functions of the two firms as

$$
\begin{gathered}
W=\int_{0}^{\infty} e^{-r t}\left[U\left(K_{1 A}, K_{1 B}, K_{2 A}, K_{2 B}\right)-\mu_{1} I_{1 A}-\frac{\gamma_{1 A}}{2} I_{1 A}^{2}\right. \\
-\mu_{2} I_{2 A}-\frac{\gamma_{2 A}}{2} I_{2 A}^{2}-\mu_{R} I_{R A}-\frac{\gamma_{R A}}{2} I_{R A}^{2}-\mu_{1} I_{1 B}-\frac{\gamma_{1 B}}{2} I_{1 B}^{2} \\
\left.\quad-\mu_{2} I_{2 B}-\frac{\gamma_{2 B}}{2} I_{2 B}^{2}-\mu_{R B} I_{R B}-\frac{\gamma_{R}}{2} I_{R B}^{2}\right] d t
\end{gathered}
$$

The social planner problem is to choose $\left(I_{1 f}, I_{2 f}, I_{r f}\right), f=A, B$ in order to maximize expected welfare $(\mathbb{E} W)$ subject to the state dynamics (1), the mode dynamics (4), as well as the state constraint (2) and the control constraints associated with the different modes. The expected innovation time under the social planner solution is then given by $\tau^{S P}=\mathbb{E} \min \left[\tau_{A}^{S P}, \tau_{B}^{S P}\right]$, where $\tau_{f}^{S P}$ is the innovation time of firm $f$ if it invests according to the strategy solving the social planner problem. 